\title{
MİKRODALGA VE TERMOSONİKASYON HASSLAMA YÖNTEMLERİ İLE PATATESİN HAŞLANMASI VE KALİTE ÖZELLİKLERİNİN BELİRLENMESİ
}

\author{
Hamza BOZKIR* \\ Sakarya Uygulamalı Bilimler Üniversitesi, Pamukova Meslek Yüksek Okulu, Gıda İșleme Bölümü, Sakarya, \\ Türkiye
}

Geliş / Received: 05.05.2020; Kabul / Accepted: 07.09.2020; Online bask1 / Published online: 25.09.2020

Bozkır, H. (2020). Mikrodalga ve termosonikasyon haşlama yöntemleri ile patatesin haşlanması ve kalite özelliklerinin belirlenmesi. GIDA (2020) 45(5) 917-928 doi: 10.15237/gida.GD20065.

Bozker, H. (2020). Blanching of potato using microwave and thermosonication blanching methods and determination of quality characteristics. GIDA (2020) 45(5) 917-928 doi: 10.15237/gida.GD20065.

\section{öz}

Geleneksel haşlama yöntemi ürünlerin renk, doku ve tatlarında istenmeyen değişimlere sebep olmakta, suda çözünür kuru madde, vitaminler, mineraller, fenolik ve karotenoid bileşenlerinde kayıplara yol açmakta ve uygulama süresinin uzun oluşu enerji maliyetlerinin artmasına neden olmaktadır. Son yıllarda, geleneksel haşlama işleminin meyve ve sebzelerde oluşturduğu olumsuzlukları önlemek için yeni teknolojilerin kullanımı ile ilgili araşturmalar önem kazanmıştr. Bu çalışma mikrodalga, termosonikasyon ve geleneksel haşlama yöntemleri ile patates peroksidaz enziminin inaktivasyonu ve örneklerin toplam kuru madde, $C$ vitamini, doku ve renk özelliklerinin karșılașturılmasını amaçlamıștır. Mikrodalga hașlama ve termosonikasyon hașlama yöntemlerinin geleneksel haşlamaya kıyasla haşlama sürelerini sırasıyla $\% 50.38-85.71$ ve $\% 57.14$ azalttuğ1 tespit edilmiştir. Termosonikasyon haşlama tekniğinin $\mathrm{C}$ vitamini, $\mathrm{L}^{*}, \mathrm{a}^{*}, \mathrm{~b}^{*}, \Delta \mathrm{E}, \Delta \mathrm{C}$ ve Hue ${ }^{\circ}$ renk değerlerini diğer yöntemlere kiyasla daha iyi koruduğu belirlenmiştir. Mikrodalga haşlama yönteminin sertlik, iç yapışkanlık, dış yapışkanlık, sakızımsılık, esneklik, elastikiyet ve çiğnenebilirlik doku özelliklerinde en yüksek değişimi gösterdiği, buna karşlllk termosonikasyon haşlama yönteminin ise en düşük değişimi oluşturduğu belirlenmiştir.

Anahtar kelimeler: Haşlama, mikrodalga, termosonikasyon, peroksidaz, kalite.

\section{BLANCHING OF POTATO USING MICROWAVE AND THERMOSONICATION BLANCHING METHODS AND DETERMINATION OF QUALITY CHARACTERISTICS}

\begin{abstract}
The traditional blanching methods cause undesirable changes in color, texture and flavor and it leads to loss of soluble solids, vitamins, minerals, and phenolic compounds, and long application time increases the energy costs. In recent years, novel blanching applications that eliminate the negative impacts of blanching in fruit and vegetables, have gained importance. This study aimed to inactivate potato peroxidase enzyme using microwave, thermosonication, and traditional blanching methods and compare total dry matter, vitamin $\mathrm{C}$, texture, and color properties of samples. The microwave blanching and the thermosonication blanching reduced blanching times $50.38-85.71 \%$ and $57.14 \%$, respectively, compared to traditional blanching. The thermosonication blanching preserved vitamin
\end{abstract}

\footnotetext{
* Yazışmalardan sorumlu yazar/ Corresponding author

$\triangle$ : bozkirhamza@gmail.com

(ग):(+90) 2646160820

且:(+90) 2646160014
}

Hamza Bozkır; ORCID no: 0000-0002-8868-697X 
$\mathrm{C}$ and color values of $\mathrm{L}^{*}, \mathrm{a} *, \mathrm{~b} *, \Delta \mathrm{E}, \Delta \mathrm{C}$, and $\mathrm{Hue}^{\circ}$. It was detected that the microwave blanching showed the highest change in tissue characteristics of hardness, cohesiveness, adhesiveness, gumminess, springiness, elasticity, and chewiness, whereas the thermosonication blanching produced the lowest change.

Keywords: Blanching, microwave, thermosonication, peroxidase, quality.

\section{GİRIŞ}

Patates, Solanum tuberosum L. türüne giren kültür bitkilerinin yumrularıdır. Patates protein, lif, kompleks karbonhidratlar, karotenoidler, $\mathrm{C}$ ve $\mathrm{B}$ vitaminleri de dahil olmak üzere mineral maddelerce ve vitaminlerce de zengin bir bileşime sahiptir (Navarre vd., 2016). Patates cips, kızartma, dondurulmuş parmak patates, nişasta, püre, patates unu, konserve gibi çeşitli ürünlerin üretilmesinde kullanılmaktadır (Garcia-Alonso ve Goni, 2000).

Meyve ve sebzelerin çeşitli ürünlere dönüștürülmeden önce ön ișlem olarak hașlama işlemi uygulanmaktadır. Hașlama ișlemi sebzelerde ön işlem olarak uygulanan önemli bir aşamayı oluşturmaktadır (Xin vd., 2015). Haşlama işlemi ürünlerde mikrobiyal yükün azaltılması, dokulardaki havanın dışarı atılması, toksik bileşenlerin uzaklaşturılması ve ürün kalitesinin arttırılması gibi avantajlar da sağlamaktadır (Sotome vd., 2009; Xiao vd., 2017). Ayrica haşlama işlemi polifenol oksidaz, pektin metilesteraz ve peroksidaz gibi enzimlerin inaktive edilmesi ile biyokimyasal reaksiyonları engellemektedir. Haşlama prosesi isıya en dirençli olan peroksidaz enzimi hedef alınarak yapılmaktadır (Soysal ve Söylemez, 2005).

Meyve sebze işleme sanayinde suda haşlama ve/veya buharla hașlama yöntemleri kullanilmaktadır (Ioannou ve Ghoul, 2013). Ancak geleneksel haşlama yöntemleri meyve ve sebzelerde suda çözünen kuru madde, vitamin, mineral, fenolik madde ve karotenoid gibi değerli biyoaktif bileșenler ile renk, doku, lezzet gibi duyusal özelliklerinde azalmalara sebep olmaktadır. Ayrıca konvansiyonel haşlama tekniklerinde proses süresinin uzun olması enerji maliyetlerinin artmasina da neden olmaktadir (Arroqui vd., 2001; Oboh, 2005; Yolmeh ve Najafzadeh, 2014). Geleneksel haşlama prosesinin meyve ve sebzelerde oluşturduğu olumsuzlukları gideren yeni haşlama uygulamalan son yıllarda önem kazanmışır. Mikrodalga, termosonikasyon, ohmik 1sıtma ve radyo frekans 1sıtma yeni hașlama teknikleri arasında bulunmaktadır (Demirdöven ve Baysal, 2008).

Mikrodalga 1sıtma dielektrik 1sıtma yöntemleri arasında yer alan, $300 \mathrm{MHz}$ ile $300 \mathrm{GHz}$ aralığında frekansa sahip iyonize olmamıs elektromanyetik ışınımdır (Schiffman, 1986). Gıdanın mikrodalga uygulaması ile 1sitılması, gidanın yüzeyine gelen mikrodalgaları absorbe etmesine ve bünyesine aldığ 1 bu elektromanyetik enerjinin etkisi sonucu polar moleküller arasında meydana gelen titreşim ve sürtünmeler sonucunda sicaklığının artması prensibine dayanmaktadır (Platts, 1991; Stephen, 1997). Gıda sanayinde mikrodalga 1sıtma yöntemi; haşlama, pişirme, pastörizasyon, enzimlerin inaktive edilmesi, ön 1sitma, kurutma ve çözündürme işlemlerinde kullanılmaktadır (Baysal vd., 2011).

Ihl vd. (1998) mikrodalga haşlama yönteminin suda haşlamaya kıyasla enginardaki C vitamini daha fazla koruduğunu tespit etmiştir. Havuç dilimlerine uygulanan mikrodalga haşlama uygulamasının fiziksel ve kimyasal açıdan daha kaliteli ürün elde etmek için geleneksel yönteme alternatif olarak kullanılabileceği belirlenmiştir (Başkaya Sezer ve Demirdöven, 2015). Benzer şekilde meyve ve sebzelere uygulanan mikrodalga hașlama yöntemi geleneksel haşlamaya kıyasla yüksek 1sıtma, kısa ișlem süresi ve örneklerdeki besin bileşenlerinde daha az kayıp oluşturması gibi birçok avantajlara sahiptir (Ramaswamy ve Fakhouri 1998; Ramesh vd., 2002; DorantesAlvarez vd., 2011; Ruiz-Ojeda ve Peñas 2013; Xiao vd., 2017; Nguyen vd., 2019; Tang vd., 2019).

Ultrases sözlük anlamı itibariyle, saniyede 20.000 veya daha fazla titreșim gerçekleștiren ses dalgaları ile enerji meydana getirilmesi olarak ifade edilmektedir. Genellikle, ultrases uygulamalarında 20 kHz'den 10 MHz'e kadar değişen frekanslar kullanılmaktadır (Dolatowski ve ark., 2007; Knorr 
ve ark., 2004). Ultrases tekniği gida endüstrisinde dondurma, dilimleme, kurutma, çözündürme, renk açma, pastörizasyon, ekstraksiyon gibi birçok işleme uygulanabilmektedir (Ergün vd., 2013). Ultrases bazı çalışmalarda enzim ve mikrobiyal inaktivasyonun sağlanmasında tek başına yeterli olurken bazilarında da yeterli inaktivasyon derecesine ulaşmak için ultrasesin 1sı ve/veya basınç gibi işlemlerle kombine edilerek kullanılması önerilmektedir. Ultrases işleminin 1sıl işlem ile kombinasyonuna termosonikasyon adı verilmektedir (Rahman 2007; McClements 1995). Termosonikasyon işleminin oluşturduğu kavitasyonun hidrojen bağlarını kırdığ1, proteinlerin ve enzimlerin polipeptid zincirlerinde Wan der vaals etkileşimleri ile ikincil ve üçüncül yapılarda değişikliklere sebep olduğu böylelikle enzimlerin biyolojik aktivitelerinin kaybolduğu ifade edilmektedir (Terefe vd., 2009; Adiamo vd., 2018).

Gamboa-Santos vd. (2012) termosonikasyon ve suda haşlama uygulamalarının havucun kalitesine etkisini araştırmışlardır. Termosonikasyon haşlamanın geleneksel haşlamaya kıyasla haşlama süresini önemli düzeyde azalttığı ve suda çözünür kuru madde, fruktoz, sakkaroz ve glikoz kaylp miktarının düşük olduğu belirtilmiştir. Yolmeh ve Najafzadeh, (2014) yeşil fasulyelere termosonikasyon ve suda haşlama tekniklerini uygulamışlardır. Termosonikasyon haşlamanın suda haşlama yöntemine kıyasla yeşil fasulyenin C vitamini ve kalitesini daha iyi koruduğu belirtilmiştir. Meyve ve sebzelerin haşlanması amaciyla kullanılan termosonikasyon haşlama tekniğinin geleneksel haşlamaya kıyasla renk değerlerini, tekstür, C vitamini, karotenidler gibi bileşenlerde daha az kayıplar oluşturduğu ve haşlama süresini azalttı̆ğ bildirilmiştir (Cruz vd., 2011; Rawson vd., 2011; Gamboa-Santos vd., 2012; Yolmeh ve Najafzadeh 2014; Amaral vd., 2016; Alvarez vd., 2019).

Literatür kapsamında, mikrodalga haşlama ve termosonikasyon haşlama tekniklerinin meyve ve sebzelerin kalite özelliklerini daha iyi koruduğu ve işlem süresini azalttı̆̆1 görülmektedir. Ancak mikrodalga haşlama, termosonikasyon haşlama ve geleneksel haşlama tekniklerinin kıyaslandığı bir çalışma bulunmamaktadır. Bu çalışma mikrodalga haşlama, termosonikasyon haşlama ve geleneksel haşlama teknikleri ile patates peroksidaz enziminin inaktivasyonu ve örneklerin toplam kuru madde, $\mathrm{C}$ vitamini, doku ve renk özellikleri açısından karşılaşurılmasını amaçlamıştır.

\section{MATERYAL VE METOT}

\section{Materyal}

Haşlama denemelerinde kullanılan patates (Russet burbank) örnekleri Özgörkey Gıda Ürünleri San. ve Tic. A.Ş. İzmir, firmasından temin edilmiştir. Analitik saflikta hidrojen peroksit, okzalik asit, boya çözeltisi (2,6-dichloroindophenol) (Merck, Almanya) ve guaiacol, askorbik asit (SigmaAldrich Corp., USA) haşlama yeterliliği ve C vitamini analizlerinde kullanılmıştır.

\section{Haşlama Yöntemleri}

Patatesler işlem öncesinde yrkanmış, kabuğu soyulmuş ve $1 \mathrm{~cm} \times 1 \mathrm{~cm} \times 1 \mathrm{~cm}$ boyutlarında küp şeklinde kesilerek, mikrodalga haşlama, termosonikasyon haşlama ve geleneksel haşlama işlemlerine tabii tutulmuştur.

\section{Geleneksel Haşlama}

Geleneksel yöntemle haşlama işlemi su banyosuna (Wise Clean, Kore) $400 \mathrm{ml}$ cam behere $90 \pm 1$ ${ }^{\circ} C^{\prime}$ 'de 1sitılmış $200 \mathrm{ml}$ demineralize su ve $40 \mathrm{~g}$ örnek (ağıllıkça 1:5) konularak ve 0-420 s boyunca her $20 \mathrm{~s}^{\mathrm{c}} \mathrm{de}$ bir peroksidaz testi kontrol edilerek gerçekleştirilmiştir.

\section{Mikrodalga Haşlama}

Mikrodalga haşlama işlemi Samsung ME732K (2450 $\mathrm{MHz}$ ve $300,450,600,800 \mathrm{~W}$ ) markal1 cihazda uygun plastik kap içerisine $40 \mathrm{~g}$ örnek konularak döner tablanın ortasına yerleştirilmiş, 0 $200 \mathrm{~s}$ boyunca her $20 \mathrm{~s}^{\mathrm{d}} \mathrm{de}$ ve son $20 \mathrm{~s}$ 'de de $5 \mathrm{~s}$ aralıklı olarak peroksidaz testi kontrol edilerek yapılmıştr.

\section{Termosonikasyon Haşlama}

Termosonikasyon haşlama işlemi Bandelin SONOPULS HD $2200(20 \mathrm{kHz}, 70 \mathrm{~W} \% 100)$ markalı ultrason cihazı ve TT 13 prob $(13 \mathrm{~mm}$ çap) kullanılarak yapılmıştır. Prob daldırma derinliği siv1 yüzeyinden $2 \pm 0.5 \mathrm{~cm}$ ye patates örneklerine ise $3 \pm 0.5 \mathrm{~cm}$ olacak şekilde 
ayarlanarak gerçekleştirilmiştir. $400 \mathrm{ml}$ cam behere $90 \pm 1{ }^{\circ} \mathrm{C}$ 'de 1 sıtıllmıs $200 \mathrm{ml}$ demineralize su ve $40 \mathrm{~g}$ örnek (ağırlıkça 1:5) konularak sürekli sistemde termosonikasyon haşlama uygulanmıştır. Sistemin sıcaklık kontrolü için su banyosu kullanılmıstır. T tipi ısıl eş, cam beherin tabanından $1 \mathrm{~cm}$ uzaklıkta ölçüm alacak şekilde yerleştirilerek sıcaklık $90^{\circ} \mathrm{C}$ 'de sabit tutulmuştur. Termosonikasyon ile haşlanan patates örnekleri 0$200 \mathrm{~s}$ boyunca her $20 \mathrm{~s}^{\mathrm{s}} \mathrm{de}$ bir peroksidaz testi kontrol edilerek gerçekleștirilmiştir.

Geleneksel haşlama ve termosonikasyon haşlama yöntemleri ile haşlanan patatesler süzgeçte $1 \mathrm{dk}$ bekletilerek örneklerdeki fazla suyun uzaklaştırılması gerçekleştirildikten sonra analizlere geçilmiştir.

\section{Analiz Yöntemleri}

\section{Peroksidaz inaktivasyonu (Haşlama yeterliliği testi)}

Haşlama yeterliliğinin belirlenmesi için peroksidaz testi yapılmıstır. 5 gr örnek alınarak, $5 \mathrm{ml}$ demineralize su ve sirasiyla \%1'lik guaiacol $(1 \mathrm{ml})$ ve $\% 0.5$ lik hidrojen peroksit çözeltisi $(1 \mathrm{ml})$ ilave edilerek kırmızımsı kahverengi bir renk gözlendiğinde test pozitif, renk oluşmamıssa negatif olarak değerlendirilmiştir (Cemeroğlu, 2010).

\section{Toplam Kuru Madde Tayini}

Hammadde ve farklı haşlama teknikleri ile haşlanan patates örneklerinin toplam kuru madde miktarları, etüvde (Nüve, Türkiye) $105{ }^{\circ} \mathrm{C}$ sıcaklıkta sabit tartıma ulaşıncaya kadar kurutulması yoluyla belirlenmiştir (AOAC, 1990).

\section{Vitamini (Askorbik Asit) Tayini}

Örneklerin C vitamini içerikleri spektrofotometrik yönteme göre Varian Cary 50 Scan (Avustralya) model spektrofotmetre kullanılarak $518 \mathrm{~nm}$ dalga boyunda absorbans değerleri okunarak gerçekleştirilmiştir. Hammadde ve farklı yöntemler ile haşlanan patates örneklerinin askorbik asit içerikleri $\mathrm{mg} / 100 \mathrm{~g} \mathrm{k.m}$. olarak verilmiştir (AOAC, 1995).

\section{Tekstür Profil Analizi}

Taze ve farklı haşlama yöntemleri ile haşlanan patateslerin tekstür profil analizi, Texture
Analyser (TA-XT Plus Stable Micro Systems, Surrey, İngiltere) cihazı ile gerçekleştirilmiştir. Patateslerin tekstür profil analizi silindirik paslanmaz çelik prob (P/36N) kullanılarak yapılmıştur. Tekstür analizi için uygulama parametreleri; test öncesi hız $1.0 \mathrm{~mm} / \mathrm{s}$, test hız1 $1.0 \mathrm{~mm} / \mathrm{s}$, test sonras $1 \mathrm{~h} 1 \mathrm{z} 1.0 \mathrm{~mm} / \mathrm{s}$, mesafe 5 $\mathrm{mm}$ ve tetikleme kuvveti $5.0 \mathrm{~kg}$ 'dır (İçier, Çokgezme ve Sabanc1, 2017). Örneklerin sertlik, iç yapışkanlık, dış yapışkanlık, sakızımsılık, esneklik, elastikiyet ve çiğnenebilirlik özellikleri saptanmıştr.

\section{Renk Tayini}

Renk özelliklerinin incelenmesinde Konica Minolta Chroma Meter CR-400 (Japan) marka renk ölçüm cihazı kullanılmışur. Aydınlık değeri olan L*; "0" siyahtan "100" beyaza kadar değişir. “ $a *$ " değeri, "-a*”ile yeşil, " $+a^{*}$ ” ile kırmızılı̆̆1 gösterir. "b*" değeri ise "-b*" ile mavi, "+b*" ile sar1luğ1 göstermektedir. Bu değerler kullanılarak toplam renk fark $(\Delta \mathrm{E})$, kroma değeri $(\Delta \mathrm{C})$ ve Hue açısı değerleri kontrol grubu referans kabul edilerek formül 1, 2 ve 3'e göre hesaplanmıştır.

$\Delta E=\sqrt{\left(\boldsymbol{L}^{*}-\boldsymbol{L}_{r e f}^{*}\right)^{2}+\left(\boldsymbol{a}^{*}-\boldsymbol{a}_{r e f}^{*}\right)^{2}+\left(\boldsymbol{b}^{*}-\boldsymbol{b}_{r e f}^{*}\right)^{2}}$

$\Delta C=\sqrt{\left(a^{*}-a_{r e f}^{*}\right)^{2}+\left(b^{*}-b_{r e f}^{*}\right)^{2}}$

$H u e^{\circ}=\tan ^{-1}\left(\frac{b^{*}}{a^{*}}\right)$

\section{İstatistiksel Analiz}

İstatistiksel değerlendirmeler \%95 güven aralığında varyans analizinden (ANOVA) yararlanilarak SPSS paket programı kullanilarak (SPSS, 2011, 20.0 for Windows Version; SPSS Inc., Chicago, Ill) Duncan çoklu testi ile yapilmıştır.

\section{SONUÇ VE TARTIŞMA}

Haşlama Uygulamalarının Karşılaştırılması

Geleneksel, mikrodalga ve termosonikasyon yöntemleri ile haşlanan patateslerin haşlama süresi (peroksidaz enziminin inaktive olduğu süre) Çizelge 1'de verilmiştir. Geleneksel haşlama ile haşlanan patateslerin haşlama süresinin $420 \mathrm{~s}$ olduğu belirlenmiştir. Patateslerin mikrodalga 
haşlama süresinin incelenen koşullarda 60 ile 200 $\mathrm{s}$ arasında değiştiği belirlenmiştir. Mikrodalga güç seviyesindeki (300, 450, 600 ve $800 \mathrm{~W}$ ) artı̧a bağlı olarak patateslerin haşlama süresinin azaldığ saptanmıştır. Aynı şekilde yapılan bir çalışmada havucun haşlanması amacıyla kullanılan mikrodalga haşlamada güç seviyesindeki $(70,210$, 350 ve 700 W) artşsa paralel olarak haşlama süresinin 720'den $60 \mathrm{~s}$ düştüğü belirlenmiştir (Soysal ve Söylemez 2005). Termosonikasyon işlemi ile haşlanan patateslerin haşlanma süresi 180 s olarak saptanmıştr. Mikrodalga haşlama ve termosonikasyon haşlama yöntemlerinin geleneksel haşlamaya kıyasla haşlama sürelerini sırasıyla \%50.38-85.71 ve \%57.14 kısalttı̆̆1 tespit edilmiştir. Yapılan bir başka çalışmada patateslerin haşlanmasında kullanılan mikrodalga haşlamanın su ya da buharda haşlama işlemlerine göre en az $\%$ daha k1sa sürede gerçekleştirildiği belirtilmiştir (Baysal vd., 2011). Mikrodalga haşlamanın, geleneksel buhar ve suda haşlamaya kıyasla peroksidaz enziminin inaktivasyon süresini bezelyede $\% 50$, havuçta $\% 44,4$ ve enginarda $\% 60$ azalttığ1 tespit edilmiştir (Baysal, 1994). RuizOjeda ve Peñas'ın (2013) çalışmasında mikrodalga ve geleneksel haşlamaların yeşil fasulyenin kalitesi üzerine etkilerini kıyaslamışlardır. Haşlama ön işlemlerinde peroksidaz enziminin inaktive edilmesi hedef alınmıştır. Geleneksel haşlama yöntemine alternatif olabilecek mikrodalga haşlama tekniğinin proses süresini azalttı̆̆ belirlenmiştir. Başkaya Sezer ve Demirdöven (2015), havuç dilimlerinin peroksidaz ve pektin metilestereaz enzimlerinin inaktive edilmesi için mikrodalga haşlama ve geleneksel haşlama uygulamalarını kullanmıştır. Mikrodalga haşlamanın (630-900 W, 170-190 s) geleneksel haşlama $\left(94{ }^{\circ} \mathrm{C}, 300 \mathrm{~s}\right)$ kiyasla haşlama süresini azalttı̆ı bildirmiştir. Aynı şekilde Severini vd. (2016) brokolinin peroksidaz enzimini inaktive etmek için mikrodalga haşlama ve geleneksel haşlama uygulamalarını kullanmışlardır. Mikrodalga haşlamanın geleneksel haşlamaya kıyasla haşlama süresini $\% 50$ azalttığ 1 bildirilmiştir. Benzer şekilde brokoli, karnabahar, mango, muz püresi, kuşkonmaz, mısır, patates, lahana, çin kerevizi ve yeşil biberin haşlanmasında geleneksel haşlamaya alternatif olarak mikrodalga haşlama kullanılmış olup haşlama süresini önemli derecede kısalttığ1 tespit edilmiştir (Dos Reis vd., 2015; Norafida, ve Aminah, 2018; Xanthakis vd., 2018; Kumarasiri vd., 2018; Nguyen vd., 2019; Tang vd., 2019).

Çizelge 1. Farklı haşlama yöntemleri için peroksidaz testi sonuçları

Table 1. Peroxidase test results for different blanching methods

\begin{tabular}{|c|c|c|c|c|c|c|c|c|c|c|c|c|c|c|c|c|c|c|c|c|c|}
\hline $\begin{array}{l}\text { Haşlama süresi } \\
\text { Blanching time (s) }\end{array}$ & 20 & 40 & 60 & 80 & 100 & 120 & 140 & 160 & 180 & 200 & 220 & 240 & 260 & 280 & 300 & 320 & 340 & 360 & 380 & 400 & 420 \\
\hline $\mathrm{GH}$ & + & + & + & + & + & + & + & + & + & + & + & + & + & + & + & + & + & + & + & + & - \\
\hline TSH & + & + & + & + & + & + & + & + & - & & & & & & & & & & & & \\
\hline MH 300 & + & + & + & + & + & + & + & + & + & - & & & & & & & & & & & \\
\hline MH 450 & + & + & + & + & + & - & & & & & & & & & & & & & & & \\
\hline MH 600 & + & + & + & - & & & & & & & & & & & & & & & & & \\
\hline MH 800 & + & + & - & & & & & & & & & & & & & & & & & & \\
\hline
\end{tabular}

GH: Geleneksel hașlama/Traditional blanching; TSH:Termosonikasyon haşlama/Thermosonication blanching; MH 300, MH 450, MH 600, MH 800: $300 \mathrm{~W}, 450 \mathrm{~W}, 600 \mathrm{~W}$ ve $800 \mathrm{~W}$ Mikrodalga haşlama/MH 300, MH 450, MH 600, MH 800: Microwave blanching at $300 \mathrm{~W}, 450 \mathrm{~W}, 600 \mathrm{~W}$, and $800 \mathrm{~W} ;(+)$ : Peroksidaz aktivitesi var/ There is peroxidase activity; (-): Peroksidaz aktivitesi yok/ There is no peroxidase activity.

Gamboa-Santos vd. (2012) yaptıkları çalışmada; geleneksel haşlama ve termosonikasyon haşlama uygulamalarının havucun kalitesine, peroksidaz ve pektin metilestraz enzimlerinin inaktivasyonu üzerine etkisini araştırmıştır. Enzimlerin inaktivasyon sürelerinin geleneksel haşlamada 60 ${ }^{\circ} \mathrm{C}^{\prime} \mathrm{de} \quad 40 \mathrm{dk}$, termosonikasyon haşlama uygulamasinda ise $60{ }^{\circ} \mathrm{C}^{\prime} \mathrm{de} 10 \mathrm{dk}$ olduğu belirlenmiştir. Cruz vd. (2006) su teresinin peroksidaz enziminin inaktive edilmesi için termosonikasyon haşlama ve geleneksel haşlama uygulamalarının etkilerini araştırmışlardır. Termosonikasyon haşlama tekniğinin geleneksel haşlamaya kıyasla daha etkin olduğu ve proses süresini kısalttı̆̆ bildirilmiştir. Aynı araştırıcılar tarafından yapılan başka bir çalışmada su teresinin haşlanmasinda kullanılan termosonikasyon haşlamanın geleneksel haşlama işlemine göre en 
az 14 kat daha kısa sürede gerçekleştirildiği belirtilmiştir (Cruz vd., 2008). Xin vd. (2015) simli pelin yaprağının (Artemisia argyi) peroksidaz enzimini inaktive edilmesi için termosonikasyon haşlama ve geleneksel haşlama uygulamalarını kullanmıştır. Termosonikasyon haşlamanın (11.94 $\mathrm{W} / \mathrm{cm}^{2}, 85^{\circ} \mathrm{C}, 60 \mathrm{~s}$ ve $20 \mathrm{kHz}$ ) geleneksel haşlamaya kıyasla haşlama süresini azalttı̆̆ ve peroksidaz enziminin \%90.7 oranında inaktive edildiği bildirmiştir. Yolmeh ve Najafzadeh, (2014) yeşil fasulyenin peroksidaz enziminin inaktive edilmesi için termosonikasyon ve geleneksel haşlama tekniklerinin etkilerini araştırmışlardır. Termosonikasyon haşlamanın $\left(1.5 \mathrm{~kW}, 20 \mathrm{kHz}, 90{ }^{\circ} \mathrm{C}, 58.27 \mathrm{~s}\right)$ geleneksel haşlama yöntemine $\left(90^{\circ} \mathrm{C}, 240 \mathrm{~s}\right)$ kiyasla haşlama süresini $\% 75$ azalttığı belirtilmiştir. Benzer şekilde havuç, patates, domates, yeşil fasülye, kırmızı biber, su teresi, çilek, guava dilimlerinin haşlanmasında termosonikasyon haşlama yöntemi kullanılmış olup, konvansiyonel haşlamaya kıyasla haşlama süresini önemli derecede kısalttı̆̆ belirlenmiş̧tir (Alexandre vd., 2011; Rawson vd., 2011; Amaral vd., 2016; Pinheiro vd., 2016; Alvarez vd., 2019).

\section{Haşlama Yöntemlilerinin Kalite Özellikleri Üzerindeki Etkileri}

Hammadde patates ve geleneksel haşlama, mikrodalga haşlama ve termosonikasyon haşlama teknikleri ile haşlanan patateslerin toplam kuru madde değerleri Çizelge 2'de verilmiştir. Hammaddenin toplam kuru madde miktar1 ortalama \%19.58 \pm 0.10 olarak saptanmıştır. Bilişli vd. (2002) bazı patates çeşitlerinin toplam kuru madde miktarlarının \%18.2 ile \%24.6 arasında değiştiğini bildirmişlerdir. Çalışmada kullanılan patatesin toplam kuru madde miktarının, daha önce yapılan çalışmalarda bulunan değerlerle uyum gösterdiği saptanmıştır. Geleneksel, mikrodalga ve termosonikasyon haşlama teknikleri ile üretilen patateslerin toplam kuru madde değerleri \%18.42-22.34 arasında değişmekte olup, gruplar arasında istatistiksel olarak fark önemli bulunmuştur $(p<0.05)$. Dos Reis vd. (2015) çalısmalarında suda, buharda, vakum altında ve mikrodalga haşlamaların brokoli ve karnabaharın toplam kuru madde değerlerini karşılaştırmıştır. Suda, buharda, vakum altında ve mikrodalga haşlama yöntemlerinin toplam kuru madde değerleri arasındaki fark anlaml bulunmuştur. Gamboa-Santos vd. (2012) termosonikasyon haşlama ile haşlanan havuçların suda haşlananlara kıyasla suda çözünür kuru madde içeriğini daha iyi koruduğu bildirilmiştir. Mikrodalga güç seviyesindeki artışa bağlı olarak patateslerin toplam kuru madde içeriğinde artsş olduğu saptanmıştır. Benzer şekilde yapılan bir çalışmada havucun haşlanması amacıyla kullanılan mikrodalga haşlamada güç seviyesinde $(360,630$ ve 900 W) artışa paralel olarak toplam kuru madde içeriğinde de artışların olduğu belirlenmiştir (Başkaya Sezer ve Demirdöven, 2015).

Hammadde ve üç farklı yöntemle haşlanan patateslerin $\mathrm{C}$ vitamini değerleri kuru madde cinsinden Çizelge 2'de gösterilmiştir. Hammadde patatese ait örneklerde $C$ vitamini değerleri 34.16 $\mathrm{g} / 100 \mathrm{~g}$ k.m. olarak tespit edilmiştir. Farklı patates türlerinin C vitamini içerikleri 22.2-121.4 g/100 g k.m. arasında değiştiği bildirilmiştir (Burgos vd., 2009). Çalışmada kullanılan patatese ait $C$ vitamini miktarının, daha önce yapılan çalışmalarda bulunan değerlerle uyum gösterdiği belirlenmiştir. Suda, mikrodalga ve termosonikasyon haşlama yöntemleri ile haşlanan patateslerin $C$ vitamini içerikleri 20.17-28.22 g/100 g k.m arasında değişmekte olup, haşlama gurupları arasındaki farkın istatistiksel açıldan önemli olduğu tespit edilmiştir $(p<0.05)$. Cruz vd. (2008) termosonikasyon haşlama ve konvansiyonel haşlama teknikleri ile haşlanan su teresinin askorbik asit içeriklerindeki kayıpları sırasılla \%6 ve $\% 71$ olarak saptanmıştır. Yolmeh ve Najafzadeh, (2014) termosonikasyon haşlamanın geleneksel haşlama yöntemine kıyasla yeşil fasulye kalitesini ve $\mathrm{C}$ vitaminini daha iyi koruduğu belirtmiştir. Gamboa-Santos vd. (2013) yaptıkları çalışmada; termosonikasyon haşlama gruplarının suda haşlamaya kıyasla daha yüksek C vitamin içeriğine sahip olduğunu bildirilmiştir. Enginarın mikrodalga, buharla ve suda haşlama yöntemlerinin uygulandığ 1 bir çalışmada peroksidaz enziminin inaktive edilmesi amaçlanmıstır. Suda haşlanan enginarlarda C vitamini kaybının \%17 olduğu, mikrodalga haşlamada ise $\mathrm{C}$ vitamini kaybının olmadığ tespit edilmiştir (Ihl vd., 1998). Ruiz-Ojeda ve Peñas'1n 
(2013) çalışmasinda mikrodalga haşlama ile geleneksel haşlamanın yeşil fasulye kalitesi üzerine etkilerini kıyaslamışlardır. Mikrodalga haşlama tekniğinin suda haşlamaya kiyasla askorbik asidi daha iyi koruduğu ifade edilmektedir. Başka bir çalışmada ise mikrodalga haşlama, suda haşlama ve buhar haşlama yöntemleri ile haşlanan tatlı misırın askorbik asit içerikleri hammaddeye kıyasla azaldığı, ancak en düşük kaybın mikrodalga haşlama grubunda olduğu belirlenmiştir (Kumarasiri vd., 2018). Tang vd. (2019) yaptklar1 çalışmada; mikrodalga haşlama ile haşlanan Çin kerevizinin suda haşlamaya kiyasla C vitamini daha iyi koruduğunu, mikrodalga ve suda haşlama grupları arasındaki fark istatiksel olarak anlamlı olduğunu bulmuştur.

Çizelge 2. Farklı yöntemler ile haşlanan patateslere ait kalite özellikleri

Table 2. Quality properties of blanched potatoes using different methods

\begin{tabular}{|c|c|c|c|c|c|c|c|}
\hline & $\begin{array}{l}\text { Hammadde } \\
\text { Raw material }\end{array}$ & $\mathrm{GH}$ & MH 300 & MH 450 & MH 600 & MH 800 & TSH \\
\hline $\begin{array}{l}\text { Toplam kuru madde } \\
\text { Total dry matter }(\%)\end{array}$ & $19.58 \pm 0.10$ & $18.42 \pm 0.33^{\mathrm{f}}$ & $20.01 \pm 0.24^{\mathrm{d}}$ & $20.84 \pm 0.16^{c}$ & $21.45 \pm 0.40^{\mathrm{b}}$ & $22.34 \pm 0.22^{\mathrm{a}}$ & $19.00 \pm 0.27 \mathrm{e}$ \\
\hline $\begin{array}{l}\text { C Vitamini } \\
\text { Vitamin C (mg/100 g d.m.) }\end{array}$ & $34.16 \pm 0.50$ & $25.40 \pm 0.43 c$ & $20.17 \pm 0.55^{\mathrm{f}}$ & $23.03 \pm 0.20^{e}$ & $24.59 \pm 0.29 \mathrm{~d}$ & $27.48 \pm 0.50^{\mathrm{b}}$ & $28.22 \pm 0.25^{\mathrm{a}}$ \\
\hline $\mathrm{L}^{*}$ & $69.40 \pm 0.91$ & $67.65 \pm 0.13^{\mathrm{a}}$ & $68.79 \pm 0.87 \mathrm{a}$ & $68.53 \pm 0.76^{a}$ & $65.35 \pm 0.94 \mathrm{~b}$ & $64.20 \pm 0.33^{\mathrm{b}}$ & $68.43 \pm 0.73^{a}$ \\
\hline$a^{*}$ & $-6.81 \pm 0.22$ & $-9.03 \pm 0.34 b c$ & $-7.94 \pm 0.12^{\mathrm{a}}$ & $-9.45 \pm 0.20^{c}$ & $-9.08 \pm 0.40^{\mathrm{bc}}$ & $-8.71 \pm 0.34 \mathrm{~b}$ & $-7.93 \pm 0.10^{a}$ \\
\hline $\mathrm{b}^{*}$ & $27.70 \pm 0.95$ & $15.64 \pm 0.24 \mathrm{c}$ & $16.17 \pm 0.31^{\mathrm{c}}$ & $24.53 \pm 0.78^{a}$ & $24.19 \pm 0.69^{a}$ & $19.29 \pm 0.27 \mathrm{~b}$ & $24.39 \pm 0.24^{a}$ \\
\hline$\Delta \mathrm{E}$ & & $12.39 \pm 0.50^{a}$ & $11.62 \pm 0.33^{\mathrm{a}}$ & $4.28 \pm 0.55^{\mathrm{d}}$ & $5.85 \pm 0.95^{c}$ & $10.07 \pm 0.41^{b}$ & $3.67 \pm 0.35^{\mathrm{d}}$ \\
\hline$\Delta \mathrm{C}$ & & $12.27 \pm 0.50^{a}$ & $11.58 \pm 0.31^{\mathrm{a}}$ & $4.15 \pm 0.53 c$ & $4.20 \pm 0.60^{c}$ & $8.62 \pm 0.32^{b}$ & $3.49 \pm 0.24 c$ \\
\hline $\mathrm{Hue}^{\circ}$ & $103.82 \pm 0.08$ & $120.00 \pm 1.23^{\mathrm{a}}$ & $116.16 \pm 0.52^{\mathrm{b}}$ & $111.07 \pm 0.39 \mathrm{~d}$ & $110.57 \pm 0.91^{\mathrm{d}}$ & $114.30 \pm 1.10^{c}$ & $108.01 \pm 0.30 \mathrm{e}$ \\
\hline $\begin{array}{l}\text { Sertlik } \\
\text { Hardness (g) }\end{array}$ & $2545.34 \pm 97.91$ & $738.63 \pm 23.05^{b}$ & $373.04 \pm 14.90^{c}$ & $309.23 \pm 15.21^{\mathrm{d}}$ & $247.44 \pm 11.86^{\mathrm{e}}$ & $221.77 \pm 7.59 \mathrm{e}$ & $944.18 \pm 32.76^{a}$ \\
\hline $\begin{array}{l}\text { Diş yapişkanlik } \\
\text { Adhesiveness }\left(\mathrm{g} \mathrm{s}^{-1}\right)\end{array}$ & $-2.60 \pm 0.44$ & $-6.62 \pm 0.60$ a & $-13.58 \pm 0.50 c$ & $-17.96 \pm 2.13^{\mathrm{d}}$ & $-23.05 \pm 1.22^{e}$ & $-26.23 \pm 1.26^{f}$ & $-10.73 \pm 0.48^{b}$ \\
\hline $\begin{array}{l}\text { Esneklik } \\
\text { Springeness }\end{array}$ & $0.868 \pm 0.019$ & $0.829 \pm 0.026^{c}$ & $0.907 \pm 0.043^{\mathrm{a}}$ & $0.915 \pm 0.009 \mathrm{a}$ & $0.899 \pm 0.005^{\mathrm{ab}}$ & $0.833 \pm 0.028^{c}$ & $0.859 \pm 0.019 \mathrm{bc}$ \\
\hline $\begin{array}{l}\text { İç yapişkanlik } \\
\text { Cohesiveness }\end{array}$ & $0.770 \pm 0.004$ & $0.710 \pm 0.018^{\mathrm{b}}$ & $0.732 \pm 0.021^{\mathrm{b}}$ & $0.765 \pm 0.016^{\mathrm{ab}}$ & $0.818 \pm 0.065^{\mathrm{a}}$ & $0.769 \pm 0.012^{\mathrm{ab}}$ & $0.716 \pm 0.010^{\mathrm{b}}$ \\
\hline $\begin{array}{l}\text { Sakızımsillk } \\
\text { Gummines }\end{array}$ & $1977.48 \pm 94.46$ & $469.83 \pm 14.64^{b}$ & $258.37 \pm 14.61^{c}$ & $231.55 \pm 6.93 \mathrm{~d}$ & $170.62 \pm 7.61^{\mathrm{f}}$ & $194.87 \pm 3.97 \mathrm{e}$ & $628.71 \pm 18.79$ \\
\hline $\begin{array}{l}\text { Çiğnenebilirlik } \\
\text { Chewiness }\end{array}$ & $1706.54 \pm 81.45$ & $449.39 \pm 32.41^{b}$ & $242.10 \pm 16.62^{c}$ & $210.96 \pm 9.22^{c}$ & $158.71 \pm 8.76^{\mathrm{d}}$ & $215.48 \pm 9.29 c$ & $554.30 \pm 26.58^{\mathrm{a}}$ \\
\hline $\begin{array}{l}\text { Elastikiyet } \\
\text { Elasticity }\end{array}$ & $0.534 \pm 0.019$ & $0.443 \pm 0.018^{\mathrm{b}}$ & $0.438 \pm 0.004^{b}$ & $0.433 \pm 0.004 \mathrm{~b}$ & $0.424 \pm 0.013^{\mathrm{b}}$ & $0.441 \pm 0.015^{\mathrm{b}}$ & $0.479 \pm 0.009 a$ \\
\hline
\end{tabular}

GH: Geleneksel hașlama/Traditional blanching; TSH:Termosonikasyon haşlama/Thermosonication blanching; MH 300, MH 450, MH 600, MH 800: $300 \mathrm{~W}, 450 \mathrm{~W}, 600 \mathrm{~W}$ ve $800 \mathrm{~W}$ Mikrodalga haşlama/MH 300, MH 450, MH 600, MH 800: Microwave blanching at $300 \mathrm{~W}, 450 \mathrm{~W}, 600 \mathrm{~W}$, and $800 \mathrm{~W}$; ${ }^{\text {a-f }}$ Aynı satırdaki farklı harflerle işaretlenen gruplar arasındaki fark istatistiksel açıdan önemlidir $(P<0.05) .{ }^{a}$ to $\mathrm{Different} \mathrm{letters} \mathrm{within} \mathrm{rows} \mathrm{are}$ significantly different $(P<0.05)$.

Taze patatesin renk değerleri sirasiyla $L^{*}$; $69.40 \pm 0.91, a^{*} ;-6.81 \pm 0.22$ ve b*; $27.70 \pm 0.95$ olarak saptanmıştır. Geleneksel haşlama, termosonikasyon haşlama ve mikrodalga haşlama teknikleri ile haşlanan patateslerin $L^{*}$ değerleri 64.20-68.43 arasında değişmekte olup, geleneksel, termosonikasyon ve mikrodalga haşlama (MH $300 \mathrm{~W}, \mathrm{MH} 450 \mathrm{~W})$ grupları arasindaki fark istatistiksel açıdan önemsiz bulunmuştur $(p>0.05)$. Bu çalışmada üç farklı yöntem ile haşlanan örneklerinin $a^{*}$ değerleri -7.93 ile -9.45 arasında değişmekte olup, geleneksel, termosonikasyon ve mikrodalga haşlama $(\mathrm{MH}$ $800 \mathrm{~W})$ grupları arasındaki fark istatistiksel açıdan anlamlı bulunmuştur ( $p<0.05)$. Haşlanan patatesin b* değerleri 15.64 ile 24.39 arasında değişmekte olup, geleneksel, termosonikasyon ve mikrodalga haşlama (MH $800 \mathrm{~W})$ grupları arasındaki farkın istatistiksel açıdan önemli bulunmuştur $(p<0.05)$. Patatesin haşlanmasında yüksek mikrodalga güç seviyesinin düşük $L^{*}, a^{*}$ ve $b^{*}$ renk değerlerini sağladığ1 tespit edilmiştir. Latorre vd. (2012) kırmızı pancarın peroksidaz ve polifenol oksidaz enzimlerin inaktive edilmesi için mikrodalga haşlama ve geleneksel haşlama uygulamalarını kullanmışlardır. Mikrodalga haşlamada mikrodalga güç seviyesindeki artışı $L^{*}, a^{*}$ ve $b^{*}$ renk değerlerinde artışa neden olduğu, ayrıca mikrodalga haşlama ve geleneksel haşlama yöntemleri arasındaki fark istatistiksel açıdan önemli bulunmuştur $(\phi<0.05)$. Kumarasiri vd. (2018) çalışmalarında suda, buharda ve 
mikrodalga haşlamaların tatlı misırın renk değerlerini karşılaştırmıştır. Suda, buharda ve mikrodalga haşlama yöntemlerinin $L^{*}, a^{*}$ ve $b^{*}$ renk değerleri arasındaki fark anlamlı bulunmuştur. Termosonikasyon haşlamanın mikrodalga ve suda haşlamalara kıyasla $L^{*}, a^{*}$ ve $b^{*}$ renk değerlerinde en az değişimi oluşturduğu belirlenmiştir. Cruz vd. (2007)'nin yaptıkları çalışmada termosonikasyon haşlamanın konvansiyonel haşlamaya kıyasla su teresinin $\mathrm{L}^{*}$, $a^{*}$ ve b* renk değerlerinde daha az değişiklikler oluşturduğu rapor edilmiştir. Amaral vd. (2016) termosonikasyon haşlama tekniğinin suda haşlamaya kıyasla patateslerin renk değerlerini daha iyi koruduğunu bildirmişlerdir.

Suda, mikrodalga ve termosonikasyon haşlama yöntemleri ile haşlanan patates örneklerinin toplam renk farkı istatistiksel açıdan anlamlı bulunmuştur $(p<0.05)$. Patates gruplarında en yüksek ve en düşük toplam renk değissimi sırasıyla geleneksel haşlama ve termosonikasyon haşlama olarak saptanmıştır. Patates örneklerinin kroma değerleri 3.49 ile 12.39 arasında değişmekte olup, üç yöntem arasındaki fark istatistiksel açıdan önemli bulunmuştur $(p<0.05)$. Patates örneklerinde en yüksek ve en düşük kroma değişimi sırasıyla geleneksel haşlama ve termosonikasyon haşlama olarak belirlenmiştir. Patates örneklerinin hue açısı değerleri 108.01 ile 120.00 arasında değişmekte olup, haşlama grupları arasındaki fark istatistiksel açıdan önemli olduğu saptanmıştır ( $p>0.05)$. Mikrodalga haşlamada mikrodalga güç seviyesindeki artışı patates örneklerinin toplam renk değişimi ve kroma değerlerinde azalmalara neden olduğu saptanmıştır. Benzer şekilde yapılan bir çalışmada havucun haşlanmasında kullanilan mikrodalga haşlamada güç seviyesindeki (360, 630 ve $900 \mathrm{~W}$ ) artışa paralel olarak toplam renk değişimi ve kroma değerlerinde azalmaların olduğu belirlenmiştir (Başkaya Sezer ve Demirdöven, 2015). Üç farklı yöntemle haşlanan patates örneklerinde toplam renk değişimi, kroma ve hue açısı renk değerlerinde en az değişimin termosonikasyon haşlama yönteminin olduğu saptanmıştır. Termosonikasyon işlemi ile haşlanan su teresi, patates, kırmızı biber, çilek ve guavanın toplam renk değişimi ve hue açısı değerlerinin geleneksel haşlama kıyasla daha az bulunduğu ve haşlama yöntemleri arasındaki fark istatiksel açıdan anlamlı olduğu tespit edilmiştir (Cruz vd., 2007; Alexandre vd., 2011; Amaral vd., 2016; Alvarez vd., 2019).

Hammadde ve geleneksel haşlama, mikrodalga haşlama ve termosonikasyon haşlama ile haşlanan patates örneklerinin doku özellikleri Çizelge 2'de gösterilmiştir. Hammaddenin sertlik değeri 2545.34士97.91 g olarak saptanmıştır. Geleneksel, mikrodalga ve termosonikasyon haşlama yöntemleri ile haşlanan patateslerin sertlik değerleri 221.77-944.18 g arasında değişmekte olup, gruplar arasinda istatistiksel olarak fark anlamlı bulunmuştur $(p<0.05)$. Geleneksel, mikrodalga ve termosonikasyon haşlama yöntemlerinin haşlanan patates örneklerinin diş yapışkanlık değerlerinin arttığ1 ve üç yöntem arasındaki farkın istatistiksel açıdan önemli olduğu saptanmışur $(p<0.05)$. Geleneksel haşlama, mikrodalga haşlama ve termosonikasyon haşlama teknikleri ile haşlanan patates örneklerinin esneklik değerleri arasındaki fark istatistiksel açıdan önemsiz bulunmuştur $(p>0.05)$. Geleneksel, mikrodalga ve termosonikasyon haşlama yöntemleri ile haşlanan patates örneklerinin sakızımsılık ve çiğnenebilirlik değerleri arasındaki fark istatistiksel açıdan önemli olduğu saptanmıştır $(p<0.05)$. Termosonikasyon haşlama ile haşlanan patates örnekleri en yüksek elastikiyet değeri gösterirken en düşük değeri ise geleneksel ve mikrodalga haşlama gruplarında olduğu tespit edilmiştir. Geleneksel haşlama ile haşlanan patates örneklerinin sertlik, iç yapışkanlık, dış yapışkanlık, sakızımsılık, esneklik, elastikiyet ve çiğnenebilirlik özelliklerinin mikrodalga haşlamaya kiyasla daha iyi korunduğu belirlenmiştir. Benzer şekilde mikrodalga haşlama ile haşlanan havuç ve kırmızı pancarın doku özelliklerinin geleneksel haşlamada daha düşük bulunmuştur (Latorre vd., 2012; Başkaya Sezer ve Demirdöven, 2015). Bunun nedeni gida maddesinin sertliğini oluşturan hemiselüloz köprüleri ve selülozun hidrojen bağlarının üzerine mikrodalga etkisinden kaynaklandığ düşünülmektedir (Latorre vd., 2013). Termosonikasyon haşlama ile haşlanan patateslerin sertlik, iç yapışkanlık, dış yapışkanlık, 
sakızımsılık, esneklik, elastikiyet ve çiğnenebilirlik özelliklerinin geleneksel ve mikrodalga haşlamalara kıyasla daha iyi olduğu saptanmıştır. Aynı şekilde termosonikasyon haşlama ile haşlanan su teresi, patates, kırmızı biber ve çileğin sertlik değerlerinin geleneksel haşlama kıyasla yüksek olduğu ve haşlama yöntemleri arasındaki fark istatiksel açıdan önemli bulunmuştur (Alexandre vd., 2011; Amaral vd., 2016).

\section{SONUÇ}

Bu çalışma patates küplerinin mikrodalga haşlama ve termosonikasyon haşlama uygulamalarının geleneksel yönteme alternatif olarak kullanılabileceğini göstermektedir. Mikrodalga haşlama ve termosonikasyon haşlama yöntemlerinin geleneksel haşlamaya kıyasla haşlama süresini azalttığ1 tespit edilmiştir. Termosonikasyon haşlama yönteminin geleneksel haşlama ve mikrodalga haşlama uygulamalarına kıyasla C vitamini koruduğu belirlenmiştir. Termosonikasyon haşlama tekniğinin renk değerlerinde $\left(\mathrm{L}^{*}, \mathrm{a}^{*}, \mathrm{~b}^{*}, \Delta \mathrm{E}, \Delta \mathrm{C}\right.$ ve $\left.\mathrm{Hue}^{\circ}\right)$ en az değişimleri gösterdiği, geleneksel haşlamanın ise en yüksek değissimlere neden olduğu tespit edilmiştir. Termosonikasyon haşlama ile haşlanan patateslerin doku özelliklerindeki değişimin en az olduğu, mikrodalga haşlama ile haşlanan örneklerde ise bu değişim en yüksek bulunmuştur. $\mathrm{Bu}$ çalışmanın meyve ve sebze işlemede mikrodalga ve termosonikasyon haşlamalarının kulanım olanağının araştırılmasında ileride yapılabilecek haşlama proseslerine yol gösterici olacağı ön görülmektedir.

\section{ÇIKAR ÇATIŞMASI BEYANI}

Yazar, bu makalenin çıkar çatışması olmadığını beyan eder.

\section{YAZAR KATKILARI}

Yazar, bu makalenin yapılmasını, yazılmasını ve yayınlanmasını sağlamıştır. Yazar makalenin son halini okudu ve onayladi.

\section{KAYNAKLAR}

Adiamo, O.Q., Ghafoor, K., Al-Juhaimi, F., Babiker, E.E., Mohamed Ahmed, I.A. (2018). Thermosonication process for optimal functional properties in carrot juice containing orange peel and pulp extracts. Food Chem, 245, 7988.

Alexandre, E.M.C., Santos-Pedro, D.M, Brandão, T.R.S., Silva, C.L.M. (2011). Study on thermosonication and ultraviolet radiation processes as an alternative to blanching for some fruits and vegetables. Food Bioprocess Technol, 4,1012-1019

Alvarez, C., Ospina, S., Orrego, C.E. (2019). Effects of ultrasound-assisted blanching on the processing and quality parameters of freeze-dried guava slices. J Food Process Preserv, 2019;00:e14288

Amaral, R.D.A.A., Benedetti, B.C., Pujolà, M. (2016). A first approach of using ultrasound as an alternative for blanching in vacuum-packaged potato strips. Food Bioprocess Technol, 9, 794-1801.

AOAC. 1990. In: (15th Edn. Ed.), Official Methods of Analysis, Association of Official Analytical Chemists, Arlington, VA.

AOAC. 1995. Ascorbic acid determination. In Official Methods of Analysis of the Association of Official Analytical Chemists, , Method No. 967.21 (K. Helrich, ed.) A.O.A.C Inc., Arlington, VA.

Arroqui, C., Rumsey, T.R., Lopez, A., Virseda, P. (2001). Effect of different soluble solids in the water on the ascorbic acid losses during water blanching of potato tissue. J Food Eng, 47, 123126.

Başkaya Sezer, D., Demirdöven, A. (2015). The Effects of Microwave Blanching Conditions on Carrot Slices: Optimization and Comparison. J Food Process Preserv, 39(6), 2188-2196.

Baysal T. (1994). Bazı Sebzelerin Kalitesine Mikrodalga ve Diğer Haşlama Yöntemlerinin Etkileri Üzerine Araştrrma. Ege Üniversitesi Fen Bilimleri Enstitüsü Gıda Mühendisliği Ana Bilim Dalı Doktora Tezi İzmir, Türkiye, 164 s.

Baysal, T., İçier, F. ve Baysal, H.A. (2011). Güncel elektriksel 1sıtma yöntemleri, Sidas Medya Yayınları, No:14-1B, 348 s, İzmir.

Bilişli, A., Çevik, İ., Şentürk, A. (2002). Bazı patates çeşitlerinin derin dondurmaya elverişliliği 
üzerine araştırmalar. Gida Yem Bil Teknol, 204; $0(1), 12-18$.

Burgos, G., Auqui, S., Amoros, W., Salas, E., Bonierbale, M. (2009). Ascorbic acid concentration of native Andean potato varieties as affected by environment, cooking and storage. J Food Compost Anal, 22, 533-538.

Cemeroğlu, B. (2010). Gıda Analizleri, (2. Basım) Ankara.

Cruz, R.M.S., Vieira, M.C., Silva, C.L.M. (2006). Effect of heat and thermosonication treatments on peroxidase inactivation kinetics in watercress (Nasturtium officinale). J Food Eng, 72:8-15.

Cruz, R.M.S., Vieira, M.C., Silva, C.L.M. (2007). Modelling kinetics of watercress (Nasturtium officinale) colour changes due to heat and thermosonication treatments. Innov Food Sci Emerg Technol 8,244-252.

Cruz, R.M.S., Vieira, M.C., Silva, C.L.M. (2008). Effect of heat and thermosonication treatments on watercress (Nasturtium officinale) vitamin C degradation kinetics. Innov Food Sci Emerg Technol, 9:483-488.

Cruz, R.M.S., Vieira, M.C., Fonseca, S.C., Silva, C.L.M. (2011). Impact of Thermal Blanching and Thermosonication Treatments on Watercress (Nasturtium officinale) Quality: Thermosonication Process Optimisation and Microstructure Evaluation. Food Bioprocess Technol, 4(7), 1197-1204.

Demirdöven, A., Baysal, T. (2008). Meyve ve sebze işleme sanayinde yeni uygulamalar, Türkiye 10. G1da Kongresi; 21-23 May1s 2008, Erzurum.

Dolatowski, Z.J., Stadnik, J., Stasiak, D. (2007). Applications of ultrasound in food technology. Acta Sci Pol Technol Aliment, 6 (3) 89-99.

Dorantes-Alvarez, L., Jaramillo-Flores, E., González, K., Martinez, R., Parada, L. (2011). Blanching peppers using microwaves. Procedia Food Sci, 1, 178-183.

Dos Reis, L.C.R., de Oliveira, V.R., Hagen, M.E.K., Jablonski, A., Flôres, S.H., de Oliveira Rios, A. (2015). Effect of cooking on the concentration of bioactive compounds in broccoli (Brassica oleracea var. Avenger) and cauliflower (Brassica oleracea var. Alphina F1) grown in an organic system. Food Chem, 172, 770777.

Ergün, A.R., Baysal, T., Bozkı1, H. (2013). Ultrases yöntemiyle karotenoidlerin ekstraksiyonu. GID A, 38 (4): 239-246.

Gamboa-Santos, J., Cristina Soria, A., PérezMateos, M., Carrasco, J. A., Montilla, A., Villamiel, M. (2013). Vitamin C content and sensorial properties of dehydrated carrots blanched conventionally or by ultrasound. Food Chem, 136(2), 782-788.

Gamboa-Santos, J., Montilla, A., Soria, A.C. (2012). Effects of conventional and ultrasound blanching on enzyme inactivation and carbohydrate content of carrots. Eur Food Res Technol, 234, 1071-1079.

Garcia-Alonso, A, Goni, I. (2000). Effect of processing on potato starch: in vitro availability and glycemic index. Nabrung, 44,19-22.

Icier, F., Cokgezme, O. F., Sabanci, S. (2017). Alternative thawing methods for the blanched/non-blanched potato cubes: microwave, ohmic, and carbon fiber plate assisted cabin thawing. J Food Process Eng, 40(2), e12403.

Ihl, M., Monsalves, M., Bifani, V. (1998). Chlorophyllase inactivation as a measure of blanching efficacy and colour retention of artichokes (Cynara scolymus L.). LWT-Food Sci Tecbnol, 31, 1, 50-56.

Ioannou, I., Ghoul, M. (2013). Prevention of enzymatic browning in fruit and vegetables. Eur Sci J, 9(30):310-341.

Knorr, D., Zenker, M., Heinz, V., Lee, D.U. (2004). Applications and potential of ultrasonic in food processing. Trends Food Sci Technol, 15: 261266.

Kumarasiri, U.W.L.M., Premakumar, K., Khurdiya, D.S. (2018). Effects of microwave blanching on the nutritional qualities of banana puree. Biol Life Sci, 12(1), 1-8.

Latorre, M.E., Bonelli, P.R., Rojas, A.M., Gerschenson, L.N. (2012) Microwave 
inactivation of red beet (Beta vulgaris L. var. conditiva) peroxidase and polyphenoloxidase and the effect of radiation on vegetable tissue quality. J Food Eng, 109:676-684.

Latorre, M.E., de Escalada Plá, M.F., Rojas, A.M., Gerschenson, L.N. (2013). Blanching of red beet (Beta vulgaris L. var. conditiva) root. Effect of hot water or microwave radiation on cell wall characteristics. LWT-Food Sci Technol, 50(1), 193203.

McClements, D.J. (1995). Advances in the application of ultrasound in food analysis and processing. Trends Food Sci Technol, 6: 293-299.

Navarre, D.A., Shakya, R., Hellman, H. (2016). Vitamins, phytonutrients, and minerals in potato. In Advances in potato chemistry and technology: Second edition, 117-166.

Nguyen, T. V. L., Tran, T. Y. N., Lam, D. T., Bach, L. G., \& Nguyen, D. C. (2019). Effects of microwave blanching conditions on the quality of green asparagus ( Asparagus officinalis L.) butt segment. Food Sci Nutr, 7, 3513-3519.

Norafida, A., Aminah, A. (2018). Effect of blanching treatments on antioxidant activity of frozen green Capsicum (Capsicum annuum L. var bell pepper). Int Food Res J, 25,4,1427-1434.

Oboh, G. (2005). Effect of blanching on the antioxidant properties of some tropical green leafy vegetables. LWT-Food Sci Technol, 38(5), 513517.

Pinheiro, J.C., Alegria, C.S.M., Abreu, M.M.M.N. (2016). Evaluation of Alternative Preservation Treatments (Water Heat Treatment, Ultrasounds, Thermosonication and UV-C Radiation) to Improve Safety and Quality of Whole Tomato. Food Bioprocess Technol, 9, 924935.

Platts, J. (1991). Microwave Ovens, Peter Pergrinus Ltd. London UK.

Rahman, S.M. (2007). Handbook of Food Preservation. (2nt Ed.). CRC Press. London. 713739.

Ramaswamy, H.S., Fakhouri, M.O. (1998). Microwave Blanching: Effect On Peroxidise
Activity, Texture, And Quality Of Frozen Vegetables. J Food Sci Technol, 35: 216-222.

Ramesh, M.N., Wolf, W., Tevini, D., Bognar, A. (2002). Microwave Blanching of Vegetables. J Food Sci, 67(1): 390-398.

Rawson, A., Tiwari, B.K., Tuohy, M.G. (2011). Effect of ultrasound and blanching pretreatments on polyacetylene and carotenoid content of hot air and freeze dried carrot discs. Ultrason Sonochem, 18,1172-1179.

Ruiz-Ojeda, L.M. Peñas, F.J. (2013). Comparison study of conventional hot-water and microwave blanching on quality of green beans. Innov Food Sci Emerg Technol, 20, s 191-197.

Schiffman, R.F. (1986) Food Product Development for Microwave Processing. Food Technol, 40(6), 94-98.

Severini, C., Giuliani. R., De Filippis, A. (2016). Influence of different blanching methods on colour, ascorbic acid and phenolics content of broccoli. J Food Sci Technol. 53, 501-510.

Sotome, I., Takenaka, M., Koseki, S., Ogasawara, Y., Nadachi, Y., Okadome, H., Isobe, S. (2009). Blanching of potato with superheated steam and hot water spray. LWT-Food Sci Technol, 42(6), 1035- 1040.

Soysal, C.., Söylemez, Z. (2005). Kinetics and inactivation of carrot peroxidase by heat treatment. J Food Eng, 68, 349-356.

Stephen, J.H. (1997). Microwave Enhanced Chemistry (Fundemantals, Sample Preparetion and Application), American Chemical Society, Washington DC., USA.

Tang, M., Sun, H., Zhang, Z., Zhao, J., Cao, J., Thakur, K., He, S. (2019). Evaluation of hot water and microwave blanching on qualities and sensory characteristics of water dropwort (Oenanthe javanica DC.). J Food Process Preserv, 43:e14104.

Terefe, N.S., Gamage, M., Vilkhu, K., Simons, L., Mawson, R., Versteeg, C. (2009). The kinetics of inactivation of pectin methylesterase and polygalacturonase in tomato juice by thermosonication. Food Chem, 117(1), 20-27. 
Xanthakis, E., Gogou, E., Taoukis, P., Ahrné, L. (2018). Effect of microwave assisted blanching on the ascorbic acid oxidase inactivation and vitamin C degradation in frozen mangoes. Innov Food Sci Emerg Technol, 48, 248-257.

Xiao, H., Pan, Z., Deng, L., El-Mashad, H. M., Yang, X., Mujumdar, A. S., Gao, Z., Zhang, Q. (2017). Recent developments and trends in thermal blanching-A comprehensive review. Inf Process Agric, 4, 101-127.
Xin, Y., Zhang, M., Yang, H., Adhikari, B. (2015). Kinetics of argy wormwood (Artemisia argyi) leaf peroxidase and chlorophyll content changes due to thermal and thermosonication treatment. $J$ Food Sci Technol, 52(1), 249-257.

Yolmeh, M., Najafzadeh, M. (2014). Optimisation and modelling green bean's ultrasound blanching. Int J Food Sci Technol, 49(12), 2678-2684. 